\title{
Generating a topological drawing of the flat part of a non- planar graph
}

\author{
S.V. Kurapovi,A, M.V. Davidovsky²,B, A.V. Tolok3,, \\ A Zaporozhye National University, Ukraine \\ в Zaporozhye Institute of Postgraduate Pedagogical Education, Ukraine \\ C Moscow State Technological University «STANKIN», Russia \\ ${ }^{1}$ ORCID: 0000-0003-4563-7227, lilili5050@rambler.ru \\ 2 ORCID: oooo-0002-9472-3351, m.davidovsky@gmail.com \\ 3 ORCID: 0000-0002-7257-9029, a.tolok@stankin.ru
}

\begin{abstract}
$\underline{\text { Abstract }}$
In this article, we consider the issues of applying the diakoptic approach to constructing a topological drawing of the planar part of a non-planar graph. It is demonstrated that the first stage of constructing a topological drawing is based on the matroid properties of the set of graph isometric cycles. In the article, we propose a method for constructing a topological drawing of the planar part of a non-planar graph using the methods of structure numbers algebra. The initial solution is based on the set of graph isometric cycles that allows application of discrete optimization methods. The second stage of joining the cycles is based on the methods of vector algebra of intersections. In the article we describe the essential mathematical concepts and structures for solving the problem of constructing a planar topological drawing of a non-planar graph. The presentation is supported by detailed illustrative examples.
\end{abstract} graph.

Keywords: graph, rotation of graph vertices, isometric cycles, planarity, planar part of a

\section{Introduction}

The problem of constructing the maximal planar subgraph of a non-planar graph is a common task in the graph visual construction. It was demonstrated in [1] that the problem of constructing a maximal planar subgraph of a non-planar graph is NP-complete. Thus, it can be solved by a restricted class of brute force search algorithms and there is no polynomial algorithm for its solvability.

We will further consider an approximate solution to the problem in a general form, without dwelling on the details of methods and algorithms, but highlighting the main stages. To solve the problem, we will follow the principles of diakoptics [2], that is, we divide the solution into interconnected parts.

Let us consider the graph $\mathbf{G}=(\mathbf{V}, \mathbf{E})$ with a numbered set of edges $\mathbf{E}=\left\{e_{1}, e_{2}, \ldots, e_{\mathrm{m}}\right\}$ and a numbered set of vertices $\mathbf{V}=\left\{v_{1}, v_{2}, \ldots, v_{\mathrm{n}}\right\}$, wherein $\operatorname{card}(\mathbf{V})=n$ and $\operatorname{card}(\mathbf{E})=m$. Next, let's select the nonseparable part of the graph.

Definition 1. By a nonseparable graph $\mathbf{G}$, we mean a connected undirected graph without loops and multiple edges, without bridges and articulation points (cut vertices), in which the degree of each vertex is more than two.

Thus, diakoptics allows applying a mathematical model based on the cyclomatic properties of a graph, and thereby connect MacLane's theorem to the solution of the problem. Then the solution process can be represented as consisting of the following two successive stages:

- constructing a maximal planar subgraph for a nonseparable subgraph; 
- adding unit edges to the solution until obtaining a separable maximal planar subgraph (even with no additional edges).

In such a model, the major role is played by graph simple cycles. Therefore, the problem of constructing a maximal planar subgraph can be reduced to the combinatorial optimization problem.

Combinatorial optimization problem: on the set of simple cycles, find a subset of independent cycles, which represents a planar subgraph and satisfies a zero value of MacLane functional and Euler's equation with the maximum number of edges.

Such a problem statement allows treating the enumeration problem as a representative of the class of combinatorial optimization problems. Hence, the well-developed mathematical framework of discrete optimization can be applied to solve the problem. In addition, the cyclomatic approach allows strictly and unambiguously describing the topological drawing of the planar part of a graph, since the independent system of cycles obtained as a result of the solution induces (generates) the rotation of graph vertices. Indeed, according to the theory of rotations, the rotation of vertices creates a topological drawing of a graph [3].

\section{Isometric cycles and matroids}

Definition 2. An isometric cycle in a graph is a simple cycle for which the shortest path between any two of its vertices consists of the edges belonging to this cycle.

An isometric cycle is essentially a special case of an isometric subgraph [4].

In other words, an isometric cycle in a graph $\mathrm{G}$ is a subgraph $\mathrm{G}^{\prime}$ in the form of a simple cycle, where between any two non-adjacent vertices of the given subgraph in the graph $G$ there are no paths of shorter length, than the paths belonging to this cycle.

We will search of a solution on the set of graph isometric cycles. The set of isometric cycles of a graph is a matroid [5].

Definition 3. A matroid $\mathrm{M}$ is a finite set $\mathbf{S}$ and a set $\mathrm{F}$ of subsets of $\mathbf{S}$ such that the following conditions, called independence conditions, are satisfied:

$\varnothing \in \mathscr{F}$

$$
\text { If } \mathrm{Z} \in \mathscr{F} \text { and } \mathrm{Y} \subseteq \mathrm{Z} \text {, then } \mathrm{Y} \in \mathscr{F}
$$

If $\mathrm{Z}$ and $\mathrm{Y}$ - are members of $\mathscr{F}$ and $|\mathrm{Z}|=|\mathrm{Y}|+1$, then exists such $\mathrm{Z} \in \mathrm{Z}-\mathrm{Y}$, that $Y \cup Z \in \mathscr{F}^{\prime}$

In expression (3), subtracting $\mathrm{Z}-\mathrm{Y}$ is understood as $\mathrm{Z} /(\mathrm{Z} \cap \mathrm{Y})$. Elements of the set $\mathrm{S}$ are called elements of the matroid M. Members of the set $\mathrm{F}$ are called sets of the matroid $\mathrm{M}$. The maximal as for inclusion independent set of the matroid $\mathrm{M}$ is called the base of the matroid $\mathrm{M}$. The set of bases of the matroid M is denoted by $\mathrm{B}(\mathrm{M})$ or simply $\mathrm{B}$.

A subset $\mathrm{S}$ that does not belong to the set $\mathrm{F}$ is called dependent. The minimal as for inclusion dependent subset $\mathrm{S}$ is called the cycle of the matroid $\mathrm{M}$. The set of cycles of the matroid $\mathrm{M}$ is denoted by $\zeta(\mathrm{M})$ or simply $\zeta$.

Let us further denote the set of graph isometric cycles by $\mathbf{C}_{\tau}$. In turn, the set of matroid bases of isometric cycles will be denoted by $\mathbf{C}_{Y}$. The basis of the linear subspace of cycles consisting of isometric cycles of cardinality equal to the cyclomatic number of the graph $v(G)=m-n+1$ will be denoted as ${ }^{c_{b}}$ and called the configuration. In turn, ${ }^{c_{b}} \in C_{b}$, where $C_{b}$ is a set of configurations. It is natural to assume that $c_{b} \subset C_{Y}$.

A set of configurations can be represented as a structural number $\mathbf{W}$, where each column (element) characterizes the configuration. On the other hand, a structural number can be represented as a product of single-line structural numbers characterizing isometric cycles passing along a selected chord. Moreover, according to the rules of the structural numbers algebra [6], the selection of a graph tree does not affect the final result. 
In turn, a subset of cycles can be associated with two vectors: the vector of cycles along the edges $\mathrm{P}_{\mathrm{e}}$, which determines the number of isometric cycles passing along the edges of the given subset, and the vector of cycles passing through the vertices $\mathrm{P}_{\mathrm{v}}$, which determines the number of isometric cycles passing through the vertices of a given subset.

The planar part of a non-planar graph must satisfy a zero value of the MacLane functional [7]:

$$
F(C)=\sum_{i=1}^{m}\left(a_{i}-2\right)\left(a_{i}-1\right)=\sum_{i=1}^{m} a_{i}^{2}-3 \sum_{i=1}^{m} a_{i}+2 m
$$

where $a_{i}-$ are coefficients of the vector $P_{e}$.

Configuration requirements:

1. The configuration should be linearly independent.

2. The value of the MacLane functional for the configuration should tend to the minimum value.

3. There should be no zero elements in the vector of cycles along the edges for the configuration.

4. The vector of cycles along the edges for the configuration must necessarily contain single elements.

5. There should be no zero elements in the vector of cycles through vertices for the configuration.

Obviously, the value of the MacLane functional for the configuration of a non-planar graph is greater than zero. Therefore, in order to achieve a zero value of the MacLane functional, it is necessary to remove some part of the cycles. We can use the operation of differentiating the structural number $\mathbf{W}$ of isometric cycles $[8,9]$ to model the the process of removing cycles by the gradient descent method.

We illustrate the process of constructing the planar part of a non-planar nonseparable graph with specific examples, as during explanation it is necessary to introduce new nonconventional terms and definitions. Let's consider the foregoing by the example of the following undirected graph.

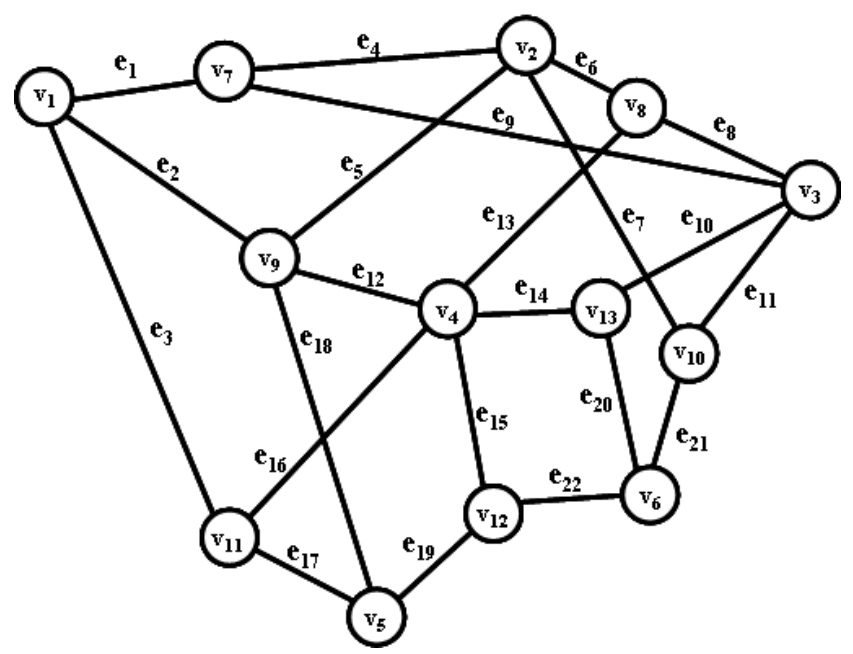

Fig. 1. Graph G.

The number of isometric cycles of the graph is 20. They are distributed according to lengths as follows: lengths 4-13 cycles, lengths 6-7 cycles.

The cycles of the corresponding matroid $\zeta\left({ }_{\tau}\right)$ consist of 6 sets, each containing 3 isometric cycles, as well as of 2 sets containing 4 cycles, and so on.

As an example, consider one of the matroid cycles shown in Fig. 2: 


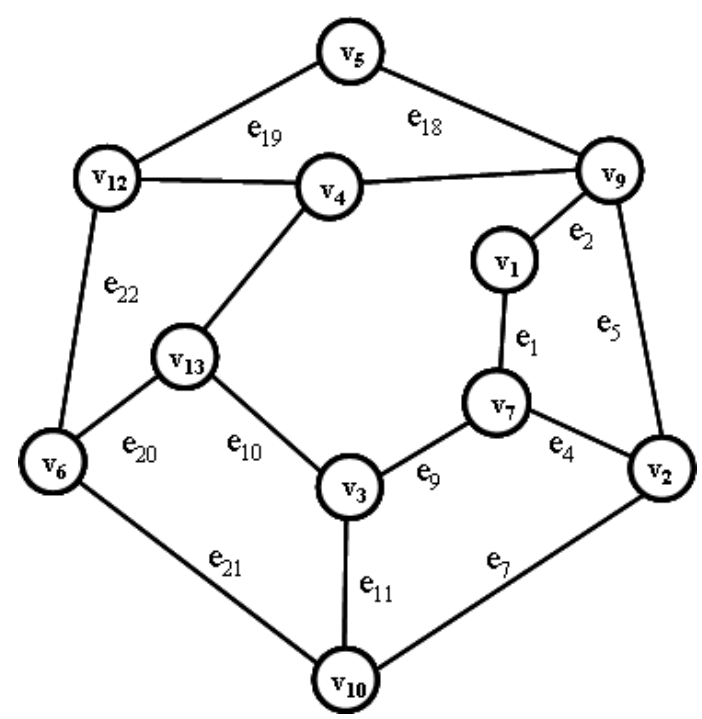

Fig. 2. A topological drawing of the $18^{\text {th }}$ cycle of the matroid.
$\mathrm{c}_{18} \oplus \mathrm{c}_{17} \oplus \mathrm{c}_{14} \oplus \mathrm{c}_{1} \oplus \mathrm{c}_{7} \oplus \mathrm{c}_{9} \oplus \mathrm{c}_{15}=\left\{\mathrm{e}_{14}, \mathrm{e}_{15}, \mathrm{e}_{20}, \mathrm{e}_{22}\right\} \oplus\left\{\mathrm{e}_{12}, \mathrm{e}_{15}, \mathrm{e}_{18}, \mathrm{e}_{19}\right\} \oplus$
$\oplus\left\{\mathrm{e}_{1}, \mathrm{e}_{2}, \mathrm{e}_{9}, \mathrm{e}_{10}, \mathrm{e}_{12}, \mathrm{e}_{14}\right\} \oplus\left\{\mathrm{e}_{1}, \mathrm{e}_{2}, \mathrm{e}_{4}, \mathrm{e}_{5}\right\} \oplus\left\{\mathrm{e}_{4}, \mathrm{e}_{7}, \mathrm{e}_{9}, \mathrm{e}_{11}\right\} \oplus\left\{\mathrm{e}_{5}, \mathrm{e}_{7}, \mathrm{e}_{18}, \mathrm{e}_{19}, \mathrm{e}_{21}, \mathrm{e}_{22}\right\} \oplus$
$\oplus\left\{\mathrm{e}_{10}, \mathrm{e}_{11}, \mathrm{e}_{20}, \mathrm{e}_{21}\right\}=\varnothing$

If we remove the following cycles from the set of isometric cycles: $\left\{\mathbf{c}_{6}, \mathbf{c}_{9}, \mathbf{c}_{14}, \mathrm{c}_{12}, \mathrm{c}_{16}, \mathrm{c}_{13}\right\}$, then we get the element of the matroid base consisting of 14 cycles.

The set of independent cycles belonging to the selected element of the matroid base will be further called the truncated set of isometric cycles. In turn, truncated sets of isometric cycles form the base of the matroid.

Next, we form single-line structural numbers for a truncated set of isometric cycles. For the selected graph tree $\mathrm{T}=\left\{\mathrm{e}_{1}, \mathrm{e}_{4}, \mathrm{e}_{5}, \mathrm{e}_{8}, \mathrm{e}_{10}, \mathrm{e}_{12}, \mathrm{e}_{13}, \mathrm{e}_{17}, \mathrm{e}_{19}, \mathrm{e}_{20}, \mathrm{e}_{21}, \mathrm{e}_{22}\right\}$ the set of chords is as follows: $\mathrm{H}=\left\{\mathrm{e}_{2}, \mathrm{e}_{3}, \mathrm{e}_{6}, \mathrm{e}_{7}, \mathrm{e}_{9}, \mathrm{e}_{11}, \mathrm{e}_{14}, \mathrm{e}_{15}, \mathrm{e}_{16}, \mathrm{e}_{18}\right\}$. And then for the set of isometric cycles, single-line structural numbers have the following form:

the cycles passing through the chord $\mathrm{e}_{2}:\left[\mathrm{c}_{1}, \mathrm{c}_{4}, \mathrm{c}_{5}, \mathrm{c}_{14}\right]$;

the cycles passing through the chord $\mathrm{e}_{3}:\left[\mathrm{c}_{2}, \mathrm{c}_{3}, \mathrm{c}_{4}, \mathrm{c}_{5}\right]$;

the cycles passing through the chord $\mathrm{e}_{6}:\left[\mathrm{c}_{6}, \mathrm{c}_{8}, \mathrm{c}_{10}, \mathrm{c}_{20}\right]$;

the cycles passing through the chord $\mathrm{e}_{7}:\left[\mathrm{c}_{7}, \mathrm{c}_{9}, \mathrm{c}_{10}, \mathrm{c}_{11}, \mathrm{c}_{12}, \mathrm{c}_{20}\right]$;

the cycles passing through the chord $\mathrm{e}_{9}:\left[\mathrm{c}_{2}, \mathrm{c}_{3}, \mathrm{c}_{6}, \mathrm{c}_{7}, \mathrm{c}_{14}\right]$;

the cycles passing through the chord $\mathrm{e}_{11}:\left[\mathrm{c}_{7}, \mathrm{c}_{10}, \mathrm{c}_{15}\right]$;

the cycles passing through the chord $\mathrm{e}_{14}:\left[\mathrm{c}_{3}, \mathrm{c}_{12}, \mathrm{c}_{13}, \mathrm{c}_{14}, \mathrm{c}_{18}\right]$;

the cycles passing through the chord $\mathrm{e}_{15}:\left[\mathrm{c}_{11}, \mathrm{c}_{17}, \mathrm{c}_{18}, \mathrm{c}_{19}, \mathrm{c}_{20}\right]$;

the cycles passing through the chord $\mathrm{e}_{16}:\left[\mathrm{c}_{2}, \mathrm{c}_{3}, \mathrm{c}_{4}, \mathrm{c}_{16}, \mathrm{c}_{19}\right]$;

the cycles passing through the chord $\mathrm{e}_{18}:\left[\mathrm{c}_{5}, \mathrm{c}_{9}, \mathrm{c}_{16}, \mathrm{c}_{17}\right]$.

We construct single-line structural numbers for a truncated set of isometric cycles. The length of an element of a structural number is always equal to the number of chords in the graph, in this case, ten.

Using the line search algorithm, we select the entire set of elements of the truncated structural number $\mathbf{W}$ and compute their number. The quantity of structural number elements for our example is 594 .

Truncated single-line structural numbers:

the cycles passing through the chord $\mathrm{e}_{14}:\left[\mathrm{c}_{3}, \mathrm{c}_{18}\right]$;

the cycles passing through the chord $\mathrm{e}_{18}:\left[\mathrm{c}_{5}, \mathrm{c}_{17}\right]$;

the cycles passing through the chord $\mathrm{e}_{2}:\left[\mathrm{c}_{1}, \mathrm{c}_{4}, \mathrm{c}_{5}\right]$;

the cycles passing through the chord $\mathrm{e}_{6}:\left[\mathrm{c}_{8}, \mathrm{c}_{10}, \mathrm{c}_{20}\right]$;

the cycles passing through the chord $\mathrm{e}_{9}:\left[\mathrm{c}_{2}, \mathrm{c}_{3}, \mathrm{c}_{7}\right]$;

the cycles passing through the chord $\mathrm{e}_{11}:\left[\mathrm{c}_{7}, \mathrm{c}_{10}, \mathrm{c}_{15}\right]$; 
the cycles passing through the chord $\mathrm{e}_{3}:\left[\mathrm{c}_{2}, \mathrm{c}_{3}, \mathrm{c}_{4}, \mathrm{c}_{5}\right]$;

the cycles passing through the chord $\mathrm{e}_{7}:\left[\mathrm{c}_{7}, \mathrm{c}_{10}, \mathrm{c}_{11}, \mathrm{c}_{20}\right]$;

the cycles passing through the chord $\mathrm{e}_{16}:\left[\mathrm{c}_{2}, \mathrm{c}_{3}, \mathrm{c}_{4}, \mathrm{c}_{19}\right]$;

the cycles passing through the chord $\mathrm{e}_{15}:\left[\mathrm{c}_{11}, \mathrm{c}_{17}, \mathrm{c}_{18}, \mathrm{c}_{19}, \mathrm{c}_{20}\right]$;

Elements of a truncated structural number (configuration) have the form (e.g., consider the $172^{\text {nd }}$ and $173^{\text {rd }}$ elements):

$172^{\text {nd }}$ element $-\left\{\mathrm{c}_{3}, \mathrm{c}_{5}, \mathrm{c}_{1}, \mathrm{c}_{20}, \mathrm{c}_{7}, \mathrm{c}_{10}, \mathrm{c}_{2}, \mathrm{c}_{11}, \mathrm{c}_{4}, \mathrm{c}_{18}\right\}$

$173^{\text {rd }}$ element $-\left\{\mathrm{c}_{3}, \mathrm{c}_{5}, \mathrm{c}_{1}, \mathrm{c}_{20}, \mathrm{c}_{7}, \mathrm{c}_{10}, \mathrm{c}_{2}, \mathrm{c}_{11}, \mathrm{c}_{4}, \mathrm{c}_{19}\right\}$

Approximately the quantity of structural number elements can be calculated by the formula:

$$
k \leq k_{u} ! /\left[\left(k_{u}-m+n-1\right) !(m-n+1) !\right]
$$

where $k_{u}-$ is the cardinality of a truncated set of isometric cycles.

Naturally, the Monte Carlo method should be used for creating practical systems of approximate solutions for isolating the planar part of a non-planar graph,. That is, using gradient descent method, randomly select a large number of configurations. Then, select the appropriate solution using the MacLane functional as the objective function and formalizing the process as taking the inverse derivative of the structural number.

The following conditions must be observed for the planar part of configuration:

1. When the cycle is excluded from the configuration (or when the operation of structural number differentiation is applied), the Pontryagin-Kuratowski functional should be used as the objective function.

2. When excluding cycles from the configuration, the rule must be fulfilled: when excluding one cycle, one and only one edge must be removed.

3. As a result of the exclusion of cycles, a subsystem of cycles should be formed that has a zero value of the Pontryagin-Kuratowski functional. Such a subsystem is called a planar configuration.

In turn, a planar configuration must satisfy a number of requirements:

1. For a planar configuration, the Euler's law must be satisfied.

2. A linear combination of cycles of a planar configuration must necessarily form a rim that characterizes a non-empty connected simple cycle.

3. The determined subgraph should be connected and should not contain articulation points.

4. The cycles of a planar configuration should induce the rotation of vertices, which describes the topological drawing of the planar part of a graph.

\section{Planar configurations for a nonseparable non-planar graph}

By randomly generating configurations using the gradient descent method, we obtain the following planar configurations:

Table 3.1. Planar configuration 1.

\begin{tabular}{|c|c|c|c|}
\hline & $\begin{array}{l}\text { The set of graph cycles } \\
\text { in the form of edges: }\end{array}$ & $\begin{array}{l}\text { The set of graph cycles } \\
\text { in the form of vertices: }\end{array}$ & $\begin{array}{l}\text { The tuple of isometric } \\
\text { cycles vertices: }\end{array}$ \\
\hline $\mathrm{c}_{16}$ & $\left\{\mathrm{e}_{12}, \mathrm{e}_{16}, \mathrm{e}_{17}, \mathrm{e}_{18}\right\}$ & $\left\{\mathrm{v}_{9}, \mathrm{v}_{5}, \mathrm{v}_{11}, \mathrm{v}_{4}\right\}$ & $\left\langle\mathrm{v}_{9}, \mathrm{v}_{5}, \mathrm{v}_{11}, \mathrm{~V}_{4}\right\rangle$ \\
\hline $\mathrm{c}_{1}$ & $\left\{\mathrm{e}_{1}, \mathrm{e}_{2}, \mathrm{e}_{4}, \mathrm{e}_{5}\right\}$ & $\left\{\mathrm{v}_{7}, \mathrm{v}_{2}, \mathrm{v}_{9}, \mathrm{v}_{1}\right\}$ & $\left\langle\mathrm{v}_{1}, \mathrm{v}_{9}, \mathrm{v}_{2}, \mathrm{v}_{7}\right\rangle$ \\
\hline $\mathrm{c}_{6}$ & $\left\{\mathrm{e}_{4}, \mathrm{e}_{6}, \mathrm{e}_{8}, \mathrm{e}_{9}\right\}$ & $\left\{\mathrm{v}_{7}, \mathrm{~V}_{3}, \mathrm{~V}_{8}, \mathrm{~V}_{2}\right\}$ & $\left\langle\mathrm{V}_{2}, \mathrm{v}_{8}, \mathrm{v}_{3}, \mathrm{~V}_{7}\right\rangle$ \\
\hline $\mathrm{c}_{8}$ & $\left\{\mathrm{e}_{5}, \mathrm{e}_{6}, \mathrm{e}_{12}, \mathrm{e}_{13}\right\}$ & $\left\{\mathrm{v}_{9}, \mathrm{v}_{4}, \mathrm{v}_{8}, \mathrm{v}_{2}\right\}$ & $\left\langle\mathrm{v}_{9}, \mathrm{v}_{4}, \mathrm{v}_{8}, \mathrm{v}_{2}\right\rangle$ \\
\hline$c_{18}$ & $\left\{\mathrm{e}_{14}, \mathrm{e}_{15}, \mathrm{e}_{20}, \mathrm{e}_{22}\right\}$ & $\left\{\mathrm{v}_{13}, \mathrm{v}_{6}, \mathrm{~V}_{12}, \mathrm{v}_{4}\right\}$ & $\left\langle\mathrm{v}_{4}, \mathrm{v}_{12}, \mathrm{~V}_{6}, \mathrm{~V}_{13}\right\rangle$ \\
\hline$c_{15}$ & $\left\{\mathrm{e}_{10}, \mathrm{e}_{11}, \mathrm{e}_{20}, \mathrm{e}_{21}\right\}$ & $\left\{\mathrm{v}_{13}, \mathrm{~V}_{6}, \mathrm{~V}_{10}, \mathrm{~V}_{3}\right\}$ & $\left\langle\mathrm{v}_{13}, \mathrm{~V}_{6}, \mathrm{~V}_{10}, \mathrm{v}_{3}\right\rangle$ \\
\hline$c_{5}$ & $\left\{\mathrm{e}_{2}, \mathrm{e}_{3}, \mathrm{e}_{17}, \mathrm{e}_{18}\right\}$ & $\left\{\mathrm{v}_{9}, \mathrm{~V}_{5}, \mathrm{~V}_{11}, \mathrm{~V}_{1}\right\}$ & $\left\langle\mathrm{v}_{1}, \mathrm{v}_{11}, \mathrm{v}_{5}, \mathrm{v}_{9}\right\rangle$ \\
\hline$c_{13}$ & $\left\{\mathrm{e}_{8}, \mathrm{e}_{10}, \mathrm{e}_{13}, \mathrm{e}_{14}\right\}$ & $\left\{\mathrm{v}_{8}, \mathrm{v}_{4}, \mathrm{v}_{13}, \mathrm{v}_{3}\right\}$ & $\left\langle\mathrm{v}_{8}, \mathrm{v}_{4}, \mathrm{v}_{13}, \mathrm{v}_{3}\right\rangle$ \\
\hline
\end{tabular}




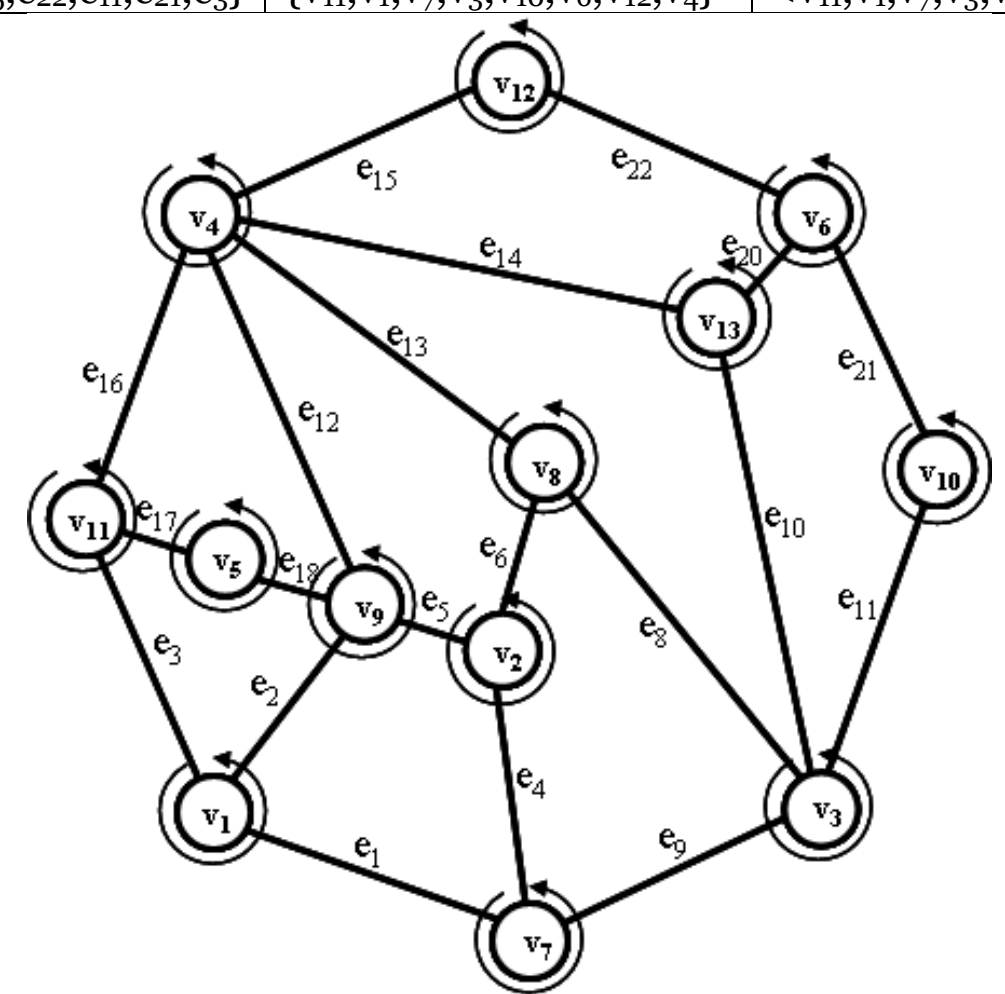

Fig. 3. Topological drawing of the planar configuration 1.

During planarization the edges $\mathrm{e}_{7}$ and $\mathrm{e}_{19}$ were removed.

Vertices rotation of the plane graph:

\begin{tabular}{|c|c|c|c|c|c|}
\hline rotation of the vertex $\mathrm{v}_{1}$ : & $\mathrm{V}_{11}$ & $\mathrm{v}_{7}$ & $\mathrm{v}_{9}$ & $\mathrm{~V}_{11}$ & \\
\hline rotation of the vertex $v_{2}$ : & $\mathrm{V}_{8}$ & $\mathrm{v}_{9}$ & $\mathrm{v}_{7}$ & $\mathrm{~V}_{8}$ & \\
\hline rotation of the vertex $\mathrm{v}_{3}$ : & $\mathrm{v}_{7}$ & $\mathrm{~V}_{10}$ & $\mathrm{~V}_{11}$ & $\mathrm{v}_{7}$ & \\
\hline rotation of the vertex $\mathrm{v}_{4}$ : & $\mathrm{V}_{11}$ & $\mathrm{v}_{9}$ & $\mathrm{~V}_{8}$ & $\mathrm{~V}_{13}$ & $\mathrm{~V}_{12}$ \\
\hline rotation of the vertex $\mathrm{v}_{5}$ : & $\mathrm{v}_{9}$ & $\mathrm{v}_{11}$ & $\mathrm{v}_{9}$ & & \\
\hline rotation of the vertex v6: & $\mathrm{V}_{13}$ & $\mathrm{~V}_{10}$ & $\mathrm{~V}_{13}$ & & \\
\hline rotation of the vertex $\mathrm{v}_{7}$ : & $\mathrm{V}_{1}$ & $\mathrm{v}_{3}$ & $\mathrm{v}_{2}$ & $\mathrm{v}_{1}$ & \\
\hline rotation of the vertex $\mathrm{v}_{8}$ : & $\mathrm{v}_{4}$ & $\mathrm{v}_{2}$ & $\mathrm{v}_{3}$ & $\mathrm{v}_{4}$ & \\
\hline rotation of the vertex $\mathrm{v}_{9}$ : & $\mathrm{v}_{4}$ & $\mathrm{v}_{5}$ & $\mathrm{v}_{1}$ & $\mathrm{v}_{2}$ & $\mathrm{v}_{4}$ \\
\hline tation of the vertex $\mathrm{v}_{10}$ : & $\mathrm{v}_{3}$ & $\mathrm{~V}_{6}$ & $\mathrm{v}_{3}$ & & \\
\hline otation of the vertex $\mathrm{v}_{11}$ : & $\mathrm{v}_{5}$ & $\mathrm{v}_{4}$ & $\mathrm{v}_{1}$ & $\mathrm{v}_{5}$ & \\
\hline tion of the vertex $\mathrm{v}_{12}$ : & $\mathrm{v}_{4}$ & $\mathrm{~V}_{6}$ & $\mathrm{v}_{4}$ & & \\
\hline tation of the vertex $v_{13}$ : & $\mathrm{v}_{4}$ & $\mathrm{v}_{3}$ & $\mathrm{v}_{6}$ & $\mathrm{v}_{4}$ & \\
\hline
\end{tabular}

Table 3.2. Planar configuration 2.

\begin{tabular}{|c|c|c|c|}
\hline & $\begin{array}{l}\text { The set of graph cycles } \\
\text { in the form of edges: }\end{array}$ & $\begin{array}{l}\text { The set of graph cycles } \\
\text { in the form of vertices: }\end{array}$ & $\begin{array}{l}\text { The tuple of isometric } \\
\text { cycles vertices: }\end{array}$ \\
\hline $\mathrm{c}_{15}$ & $\left\{\mathrm{e}_{10}, \mathrm{e}_{11}, \mathrm{e}_{20}, \mathrm{e}_{21}\right\}$ & $\left\{\mathrm{v}_{13}, \mathrm{v}_{6}, \mathrm{v}_{10}, \mathrm{v}_{3}\right\}$ & $\left\langle\mathrm{V}_{13}, \mathrm{~V}_{6}, \mathrm{~V}_{10}, \mathrm{~V}_{3}\right\rangle$ \\
\hline $\mathrm{c}_{8}$ & $\left\{\mathrm{e}_{5}, \mathrm{e}_{6}, \mathrm{e}_{12}, \mathrm{e}_{13}\right\}$ & $\left\{\mathrm{v}_{9}, \mathrm{v}_{4}, \mathrm{v}_{8}, \mathrm{v}_{2}\right\}$ & $\left\langle\mathrm{v}_{9}, \mathrm{v}_{4}, \mathrm{v}_{8}, \mathrm{v}_{2}\right\rangle$ \\
\hline $\mathrm{c}_{16}$ & $\left\{\mathrm{e}_{12}, \mathrm{e}_{16}, \mathrm{e}_{17}, \mathrm{e}_{18}\right\}$ & $\left\{\mathrm{v}_{9}, \mathrm{v}_{5}, \mathrm{v}_{11}, \mathrm{v}_{4}\right\}$ & $\left\langle\mathrm{v}_{9}, \mathrm{v}_{5}, \mathrm{v}_{11}, \mathrm{v}_{4}\right\rangle$ \\
\hline $\mathrm{c}_{13}$ & $\left\{\mathrm{e}_{8}, \mathrm{e}_{10}, \mathrm{e}_{13}, \mathrm{e}_{14}\right\}$ & $\left\{\mathrm{v}_{8}, \mathrm{v}_{4}, \mathrm{v}_{13}, \mathrm{v}_{3}\right\}$ & $\left.<\mathrm{v}_{8}, \mathrm{v}_{4}, \mathrm{v}_{13}, \mathrm{v}_{3}\right\rangle$ \\
\hline$c_{5}$ & $\left\{\mathrm{e}_{2}, \mathrm{e}_{3}, \mathrm{e}_{17}, \mathrm{e}_{18}\right\}$ & $\left\{\mathrm{v}_{9}, \mathrm{v}_{5}, \mathrm{v}_{11}, \mathrm{v}_{1}\right\}$ & $\left\langle\mathrm{V}_{1}, \mathrm{v}_{11}, \mathrm{v}_{5}, \mathrm{v}_{9}\right\rangle$ \\
\hline $\mathrm{c}_{6}$ & $\left\{\mathrm{e}_{4}, \mathrm{e}_{6}, \mathrm{e}_{8}, \mathrm{e}_{9}\right\}$ & $\left\{\mathrm{v}_{7}, \mathrm{v}_{3}, \mathrm{v}_{8}, \mathrm{v}_{2}\right\}$ & $\left\langle\mathrm{v}_{2}, \mathrm{v}_{8}, \mathrm{v}_{3}, \mathrm{v}_{7}\right\rangle$ \\
\hline $\mathrm{c}_{18}$ & $\left\{\mathrm{e}_{14}, \mathrm{e}_{15}, \mathrm{e}_{20}, \mathrm{e}_{22}\right\}$ & $\left\{\mathrm{v}_{13}, \mathrm{v}_{6}, \mathrm{v}_{12}, \mathrm{v}_{4}\right\}$ & $\left\langle\mathrm{v}_{4}, \mathrm{v}_{12}, \mathrm{~V}_{6}, \mathrm{v}_{13}\right\rangle$ \\
\hline $\mathrm{c}_{7}$ & $\left\{\mathrm{e}_{4}, \mathrm{e}_{7}, \mathrm{e}_{9}, \mathrm{e}_{11}\right\}$ & $\left\{\mathrm{v}_{7}, \mathrm{v}_{3}, \mathrm{v}_{10}, \mathrm{v}_{2}\right\}$ & $\left\langle\mathrm{v}_{7}, \mathrm{v}_{3}, \mathrm{v}_{10}, \mathrm{v}_{2}>\right.$ \\
\hline rim & $\left\{\mathrm{e}_{21}, \mathrm{e}_{5}, \mathrm{e}_{16}, \mathrm{e}_{2}, \mathrm{e}_{3}, \mathrm{e}_{15}, \mathrm{e}_{22}, \mathrm{e}_{7}\right\}$ & $\left\{\mathrm{V}_{10}, \mathrm{~V}_{2}, \mathrm{~V}_{9}, \mathrm{~V}_{1}, \mathrm{~V}_{11}, \mathrm{~V}_{4}, \mathrm{~V}_{12}, \mathrm{~V}_{6}\right\}$ & $\left\langle\mathrm{V}_{6}, \mathrm{~V}_{12}, \mathrm{~V}_{4}, \mathrm{~V}_{11}, \mathrm{~V}_{1}, \mathrm{~V}_{9}, \mathrm{~V}_{2}, \mathrm{~V}_{10}\right\rangle$ \\
\hline
\end{tabular}




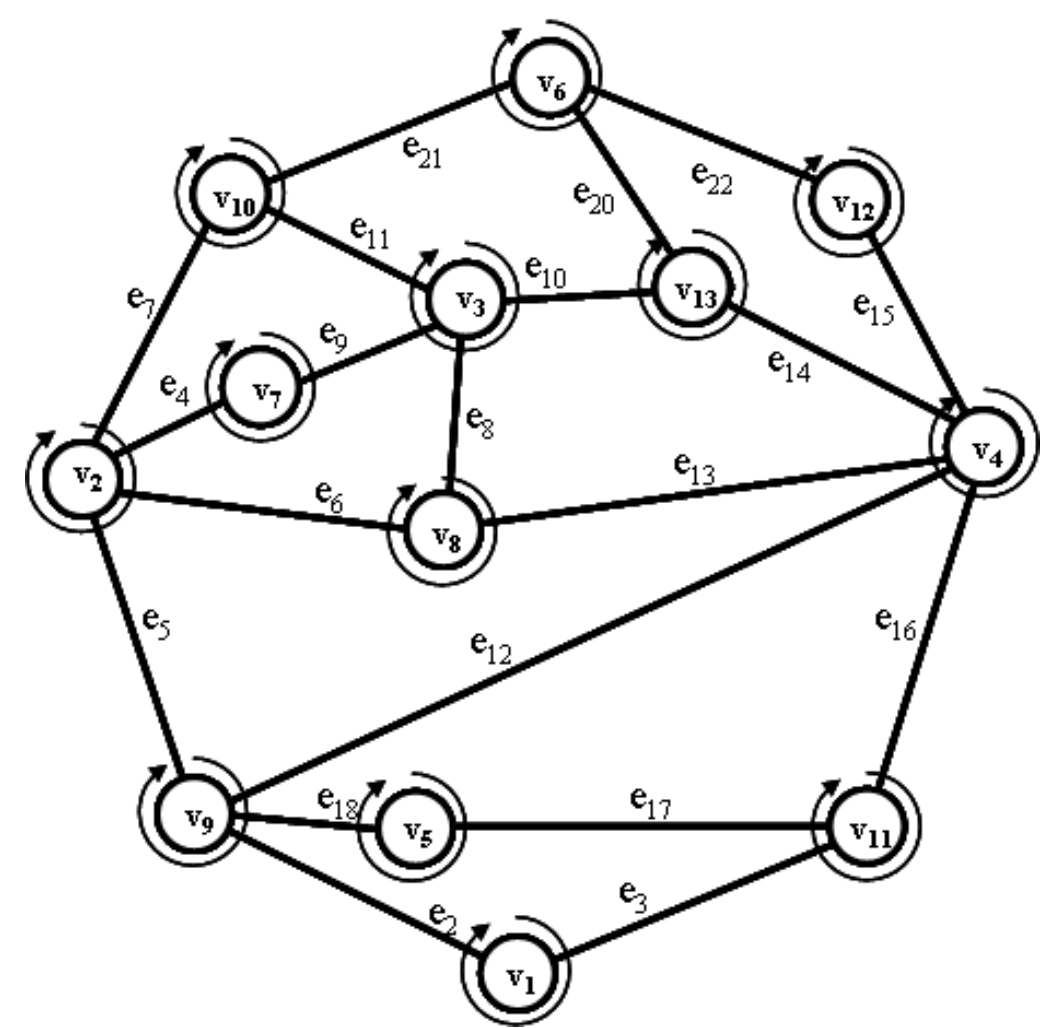

Fig. 4. Planar configuration 2.

During planarization the edges $\mathrm{e}_{1}$ and $\mathrm{e}_{19}$ were removed.

Vertices rotation of the plane graph:

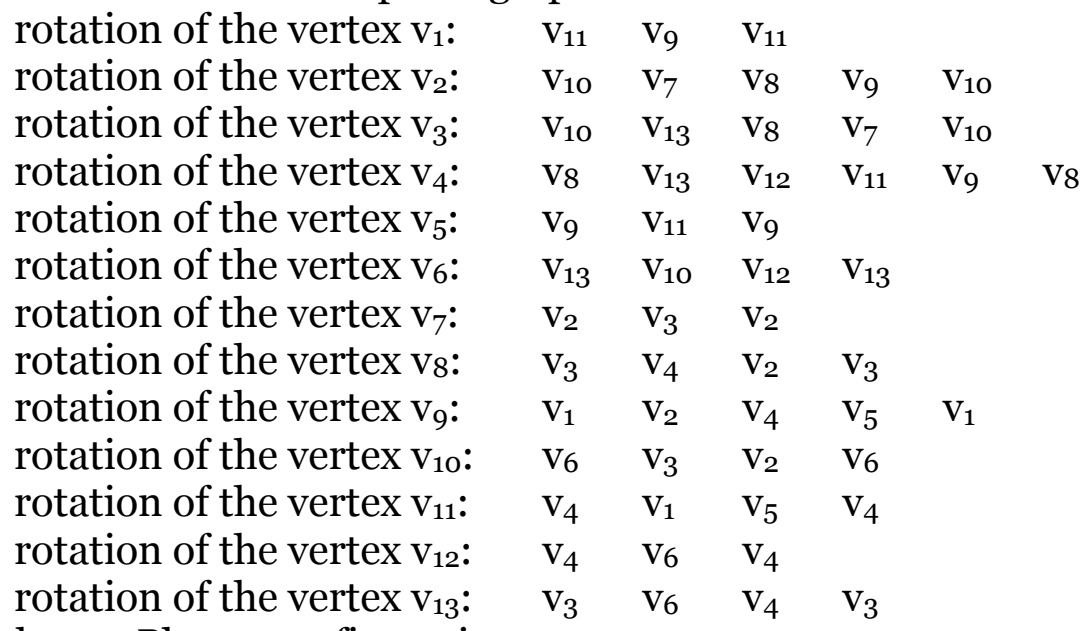

Table 3.3. Planar configuration 3.

\begin{tabular}{|l|l|l|l|}
\hline & $\begin{array}{l}\text { The set of graph cycles } \\
\text { in the form of edges: }\end{array}$ & $\begin{array}{l}\text { The set of graph cycles } \\
\text { in the form of vertices: }\end{array}$ & $\begin{array}{l}\text { The tuple of isometric } \\
\text { cycles vertices: }\end{array}$ \\
\hline $\mathrm{c}_{8}$ & $\left\{\mathrm{e}_{5}, \mathrm{e}_{6}, \mathrm{e}_{12}, \mathrm{e}_{13}\right\}$ & $\left\{\mathrm{v}_{9}, \mathrm{v}_{4}, \mathrm{v}_{8}, \mathrm{v}_{2}\right\}$ & $<\mathrm{v}_{9}, \mathrm{v}_{4}, \mathrm{v}_{8}, \mathrm{v}_{2}>$ \\
\hline $\mathrm{c}_{13}$ & $\left\{\mathrm{e}_{8}, \mathrm{e}_{10}, \mathrm{e}_{13}, \mathrm{e}_{14}\right\}$ & $\left\{\mathrm{v}_{8}, \mathrm{v}_{4}, \mathrm{v}_{13}, \mathrm{v}_{3}\right\}$ & $<\mathrm{v}_{8}, \mathrm{v}_{4}, \mathrm{v}_{13}, \mathrm{v}_{3}>$ \\
\hline $\mathrm{c}_{17}$ & $\left\{\mathrm{e}_{12}, \mathrm{e}_{15}, \mathrm{e}_{18}, \mathrm{e}_{19}\right\}$ & $\left\{\mathrm{v}_{9}, \mathrm{v}_{5}, \mathrm{v}_{12}, \mathrm{v}_{4}\right\}$ & $<\mathrm{v}_{9}, \mathrm{v}_{5}, \mathrm{v}_{12}, \mathrm{v}_{4}>$ \\
\hline $\mathrm{c}_{18}$ & $\left\{\mathrm{e}_{14}, \mathrm{e}_{15}, \mathrm{e}_{20}, \mathrm{e}_{22}\right\}$ & $\left\{\mathrm{v}_{13}, \mathrm{v}_{6}, \mathrm{v}_{12}, \mathrm{v}_{4}\right\}$ & $<\mathrm{v}_{4}, \mathrm{v}_{12}, \mathrm{v}_{6}, \mathrm{v}_{13}>$ \\
\hline $\mathrm{c}_{6}$ & $\left\{\mathrm{e}_{4}, \mathrm{e}_{6}, \mathrm{e}_{8}, \mathrm{e}_{9}\right\}$ & $\left\{\mathrm{v}_{7}, \mathrm{v}_{3}, \mathrm{v}_{8}, \mathrm{v}_{2}\right\}$ & $\left.<\mathrm{v}_{2}, \mathrm{v}_{8}, \mathrm{v}_{3}, \mathrm{v}_{7}\right\rangle$ \\
\hline $\mathrm{c}_{15}$ & $\left\{\mathrm{e}_{10}, \mathrm{e}_{11}, \mathrm{e}_{20}, \mathrm{e}_{21}\right\}$ & $\left\{\mathrm{v}_{13}, \mathrm{v}_{6}, \mathrm{v}_{10}, \mathrm{v}_{3}\right\}$ & $<\mathrm{v}_{13}, \mathrm{v}_{6}, \mathrm{v}_{10}, \mathrm{v}_{3}>$ \\
\hline $\mathrm{c}_{5}$ & $\left\{\mathrm{e}_{2}, \mathrm{e}_{3}, \mathrm{e}_{17}, \mathrm{e}_{18}\right\}$ & $\left\{\mathrm{v}_{9}, \mathrm{v}_{5}, \mathrm{v}_{11}, \mathrm{v}_{1}\right\}$ & $<\mathrm{v}_{1}, \mathrm{v}_{11}, \mathrm{v}_{5}, \mathrm{v}_{9}>$ \\
\hline $\mathrm{c}_{1}$ & $\left\{\mathrm{e}_{1}, \mathrm{e}_{2}, \mathrm{e}_{4}, \mathrm{e}_{5}\right\}$ & $\left\{\mathrm{v}_{7}, \mathrm{v}_{2}, \mathrm{v}_{9}, \mathrm{v}_{1}\right\}$ & $\left.<\mathrm{v}_{1}, \mathrm{v}_{9}, \mathrm{v}_{2}, \mathrm{v}_{7}\right\rangle$ \\
\hline $\operatorname{rim}$ & $\left\{\mathrm{e}_{19}, \mathrm{e}_{22}, \mathrm{e}_{9}, \mathrm{e}_{11}, \mathrm{e}_{21}, \mathrm{e}_{3}, \mathrm{e}_{17}, \mathrm{e}_{1}\right\}$ & $\left\{\mathrm{v}_{12}, \mathrm{v}_{6}, \mathrm{v}_{10}, \mathrm{v}_{3}, \mathrm{v}_{7}, \mathrm{v}_{1}, \mathrm{v}_{11}, \mathrm{v}_{5}\right\}$ & $\left.<\mathrm{v}_{5}, \mathrm{v}_{11}, \mathrm{v}_{1}, \mathrm{v}_{7}, \mathrm{v}_{3}, \mathrm{v}_{10}, \mathrm{v}_{6}, \mathrm{v}_{12}\right\rangle$ \\
\hline
\end{tabular}




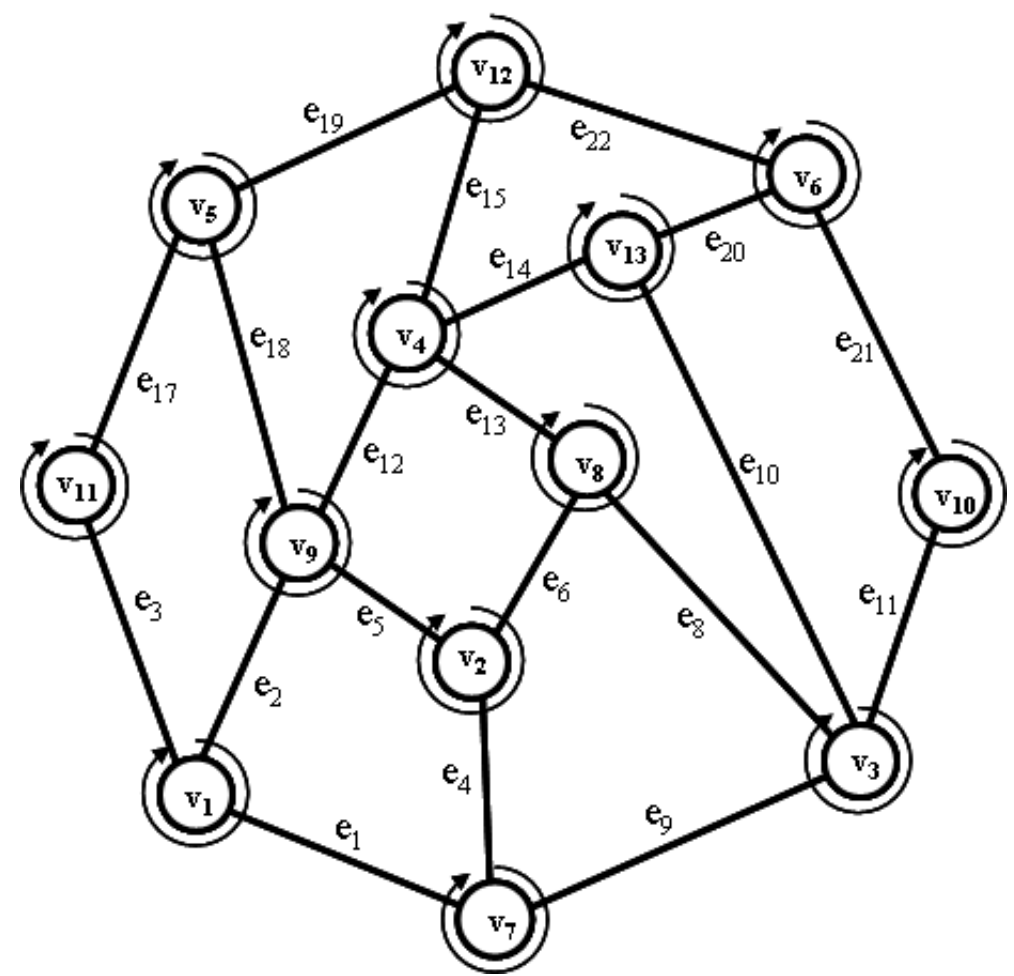

Fig. 5. Planar configuration 3 .

During planarization the edges $\mathrm{e}_{7}$ and $\mathrm{e}_{16}$ were removed.

Vertices rotation of the plane subgraph:

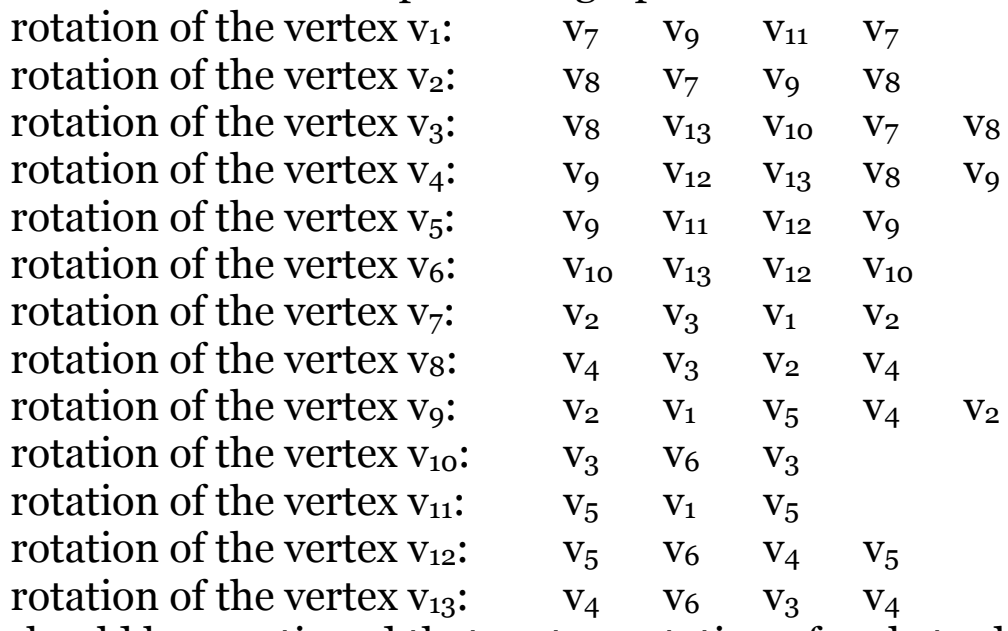

It should be mentioned that vertex notation of cycle tuples allows to write down cycles in vector form:

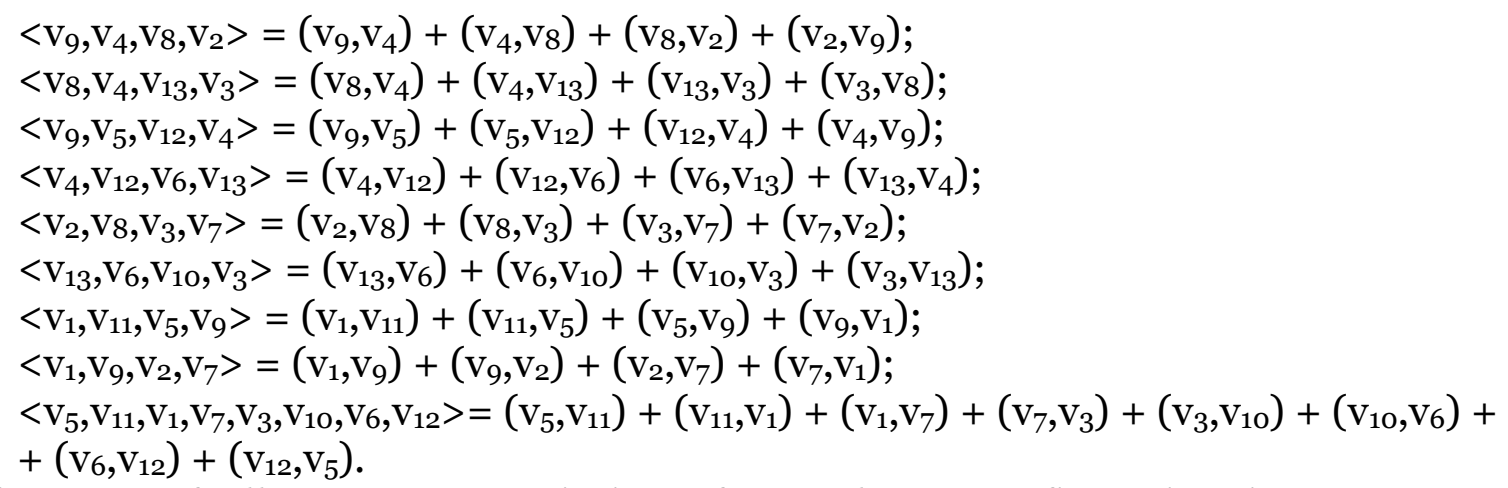

The sum of all vector transcriptions for a planar configuration is an empty set, since $\left(v_{i}, v_{j}\right)+\left(v_{j}, v_{i}\right)=\varnothing$ 
It should be noted that the subset of cycles characterized by a zero value of the PontryaginKuratowski functional (or the MacLane functional) cannot be a planar configuration, since it represents a subgraph with an articulation point (r.t. Fig. 6 for illustration).

\begin{tabular}{|l|l|l|}
\hline $\mathrm{c}_{13}$ & $\left\{\mathrm{e}_{8}, \mathrm{e}_{10}, \mathrm{e}_{13}, \mathrm{e}_{14}\right\}$ & $\left\{\mathrm{v}_{8}, \mathrm{v}_{4}, \mathrm{~V}_{13}, \mathrm{~V}_{3}\right\}$ \\
\hline $\mathrm{c}_{17}$ & $\left\{\mathrm{e}_{12}, \mathrm{e}_{15}, \mathrm{e}_{18}, \mathrm{e}_{19}\right\}$ & $\left\{\mathrm{v}_{9}, \mathrm{v}_{5}, \mathrm{v}_{12}, \mathrm{v}_{4}\right\}$ \\
\hline $\mathrm{c}_{18}$ & $\left\{\mathrm{e}_{14}, \mathrm{e}_{15}, \mathrm{e}_{20}, \mathrm{e}_{22}\right\}$ & $\left\{\mathrm{v}_{13}, \mathrm{~V}_{6}, \mathrm{~V}_{12}, \mathrm{~V}_{4}\right\}$ \\
\hline $\mathrm{c}_{15}$ & $\left\{\mathrm{e}_{10}, \mathrm{e}_{11}, \mathrm{e}_{20}, \mathrm{e}_{21}\right\}$ & $\left\{\mathrm{v}_{13}, \mathrm{v}_{6}, \mathrm{~V}_{11}, \mathrm{~V}_{3}\right\}$ \\
\hline $\mathrm{c}_{16}$ & $\left\{\mathrm{e}_{12}, \mathrm{e}_{16}, \mathrm{e}_{17}, \mathrm{e}_{18}\right\}$ & $\left\{\mathrm{v}_{9}, \mathrm{v}_{5}, \mathrm{~V}_{11}, \mathrm{~V}_{4}\right\}$ \\
\hline $\mathrm{c}_{1}$ & $\left\{\mathrm{e}_{1}, \mathrm{e}_{2}, \mathrm{e}_{4}, \mathrm{e}_{5}\right\}$ & $\left\{\mathrm{v}_{7}, \mathrm{~V}_{2}, \mathrm{v}_{9}, \mathrm{~V}_{1}\right\}$ \\
\hline
\end{tabular}

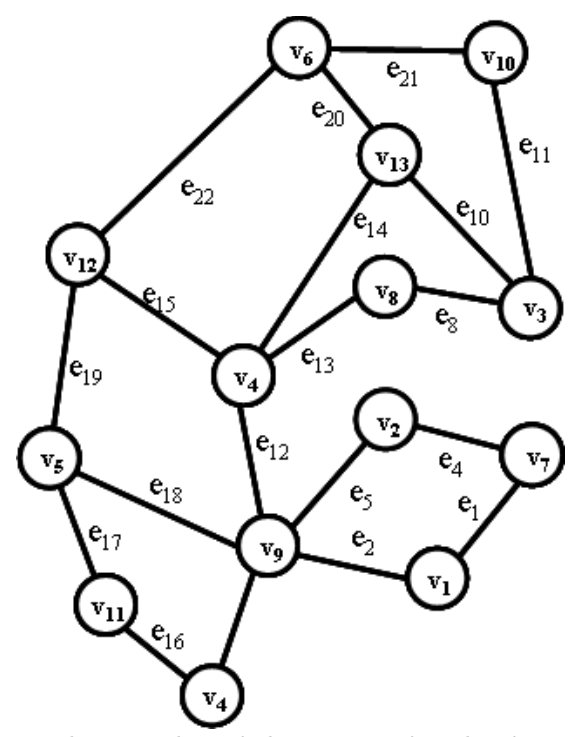

Fig. 6. Subgraph with an articulation point.

\section{The stage of adding cycles to a planar configuration}

Now let us consider the next step in constructing the topological drawing of a planar subgraph. The theoretical rationale for this method is described in details in [10-11].

We consider this stage using the example of the following graph defined by the incidentor. In this graph, we select one of the planar configurations, e.g., the following (Fig. 7).

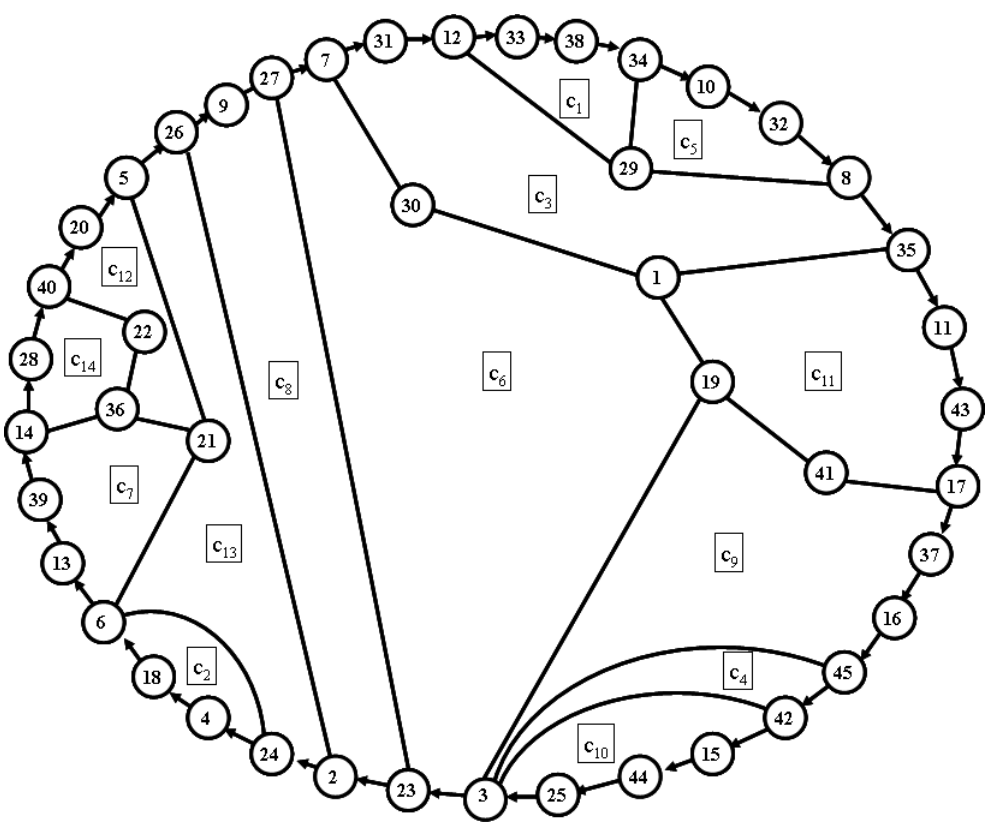

Fig.7. Topological drawing of a planar configuration. 
Consider the rim of this planar configuration as a closed sequence of oriented edges. We call such a construction the coordinate-base system (CBS) [10,11]. Let's draw the edges removed during the planarization process, which have two endpoint vertices compatible with the vertices of the rim (see Fig. 7).

We write CBS in the form of a closed tuple consisting of oriented edges $<\mathrm{e}_{44}, \mathrm{e}_{70}, \mathrm{e}_{71}, \mathrm{e}_{39}, \mathrm{e}_{38}, \mathrm{e}_{32}, \mathrm{e}_{33}, \mathrm{e}_{40}, \mathrm{e}_{41}, \mathrm{e}_{58}, \mathrm{e}_{56}, \mathrm{e}_{53}, \mathrm{e}_{55}, \mathrm{e}_{72}, \mathrm{e}_{51}, \mathrm{e}_{52}, \mathrm{e}_{67}, \mathrm{e}_{14}, \mathrm{e}_{13}, \mathrm{e}_{6}, \mathrm{e}_{7}, \mathrm{e}_{18}, \mathrm{e}_{17}, \mathrm{e}_{25}, \mathrm{e}_{24}, \mathrm{e}_{46}, \mathrm{e}_{49}, \mathrm{e}_{47}$, $\mathrm{e}_{68}, \mathrm{e}_{60}, \mathrm{e}_{20}, \mathrm{e}_{23}, \mathrm{e}_{35}, \mathrm{e}_{36}, \mathrm{e}_{28}, \mathrm{e}_{30}, \mathrm{e}_{43}>$. An undirected edge can be represented as two oppositely oriented directed edges (arcs or arrows). Then for each arc there is a projection (in the settheoretic sense) onto the coordinate-base system. Exempli gratia (Fig. 8):

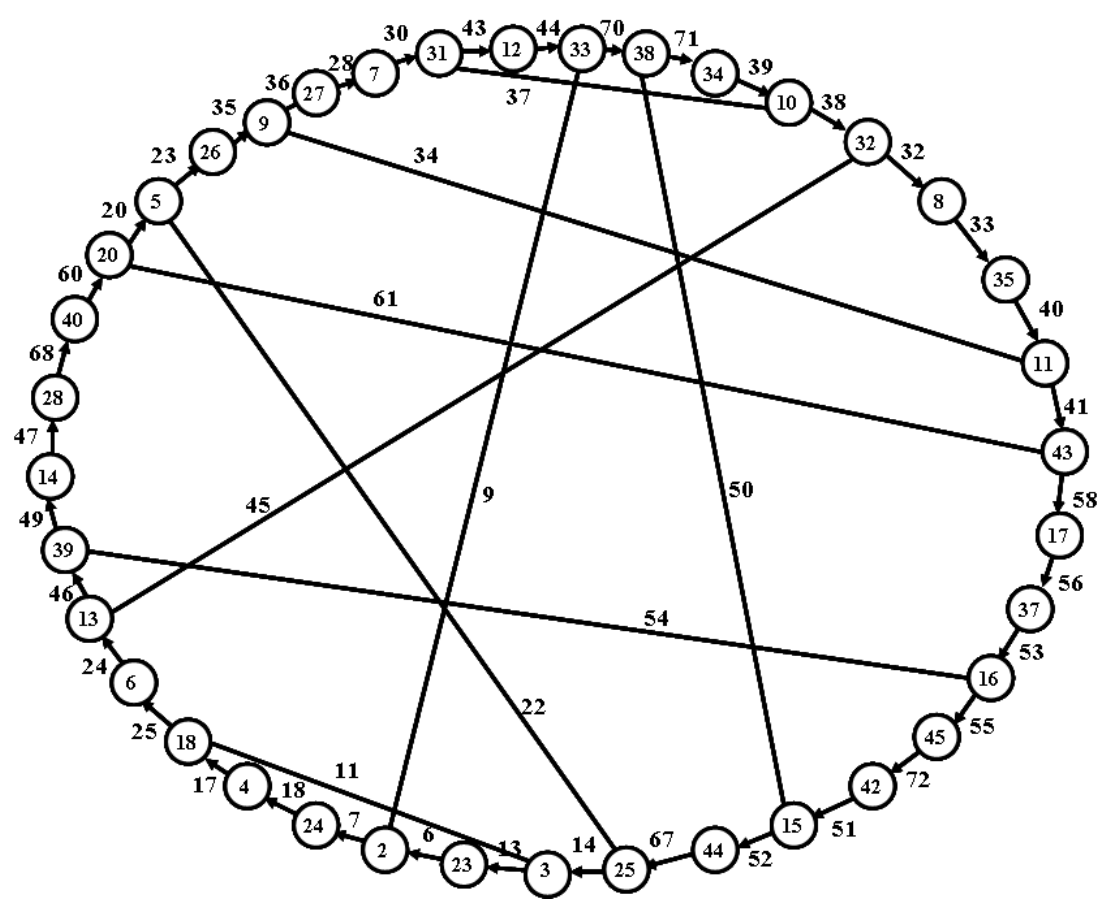

Fig. 8. Coordinate-base system and drawn edges.

From two projections of the edge we select one projection, which has the minimum length. In accordance with the laws of the vector algebra of intersections, we assume that the edges intersect if their projections intersect (in terms of the set-theory). The edges do not intersect if the result of the intersection of their projections is an empty set or one projection is completely included into another.

Consider the intersections of the edge $e_{9}$. From consideration follows that the edge $e_{9}$ intersects with all edges except the edge $\mathrm{e}_{50}$.

To determine the removal of edges, it is necessary to consider all cases of pairwise intersection of edges. After that, we can sequentially remove edges that maximally intersect with others. At the end of the process, the set of disjoint edges are isolated. For our example case, the disjoint edges are shown in Fig. 9.

As a result, we obtain new simple cycles that can be added to existing ones.

$\mathrm{c}_{15}=\left\{\mathrm{e}_{37}, \mathrm{e}_{43}, \mathrm{e}_{41}, \mathrm{e}_{70}, \mathrm{e}_{71}, \mathrm{e}_{39}\right\} ;$

$\mathrm{c}_{16}=\left\{\mathrm{e}_{37}, \mathrm{e}_{38}, \mathrm{e}_{32}, \mathrm{e}_{33}, \mathrm{e}_{40}, \mathrm{e}_{34}, \mathrm{e}_{36}, \mathrm{e}_{28}, \mathrm{e}_{30}\right\} ;$

$\mathrm{c}_{17}=\left\{\mathrm{e}_{34}, \mathrm{e}_{41}, \mathrm{e}_{61}, \mathrm{e}_{20}, \mathrm{e}_{23}, \mathrm{e}_{35}\right\} ;$

$\mathrm{c}_{18}=\left\{\mathrm{e}_{54}, \mathrm{e}_{55}, \mathrm{e}_{72}, \mathrm{e}_{51}, \mathrm{e}_{52}, \mathrm{e}_{67}, \mathrm{e}_{11}, \mathrm{e}_{25}, \mathrm{e}_{24}, \mathrm{e}_{46}\right\} ;$

$\mathrm{c}_{19}=\left\{\mathrm{e}_{11}, \mathrm{e}_{17}, \mathrm{e}_{18}, \mathrm{e}_{6}, \mathrm{e}_{7}, \mathrm{e}_{15}\right\} ;$

$c_{0}=\left\{\mathrm{e}_{61}, \mathrm{e}_{58}, \mathrm{e}_{56}, \mathrm{e}_{53}, \mathrm{e}_{54}, \mathrm{e}_{49}, \mathrm{e}_{47}, \mathrm{e}_{68}, \mathrm{e}_{60}\right\}$. 


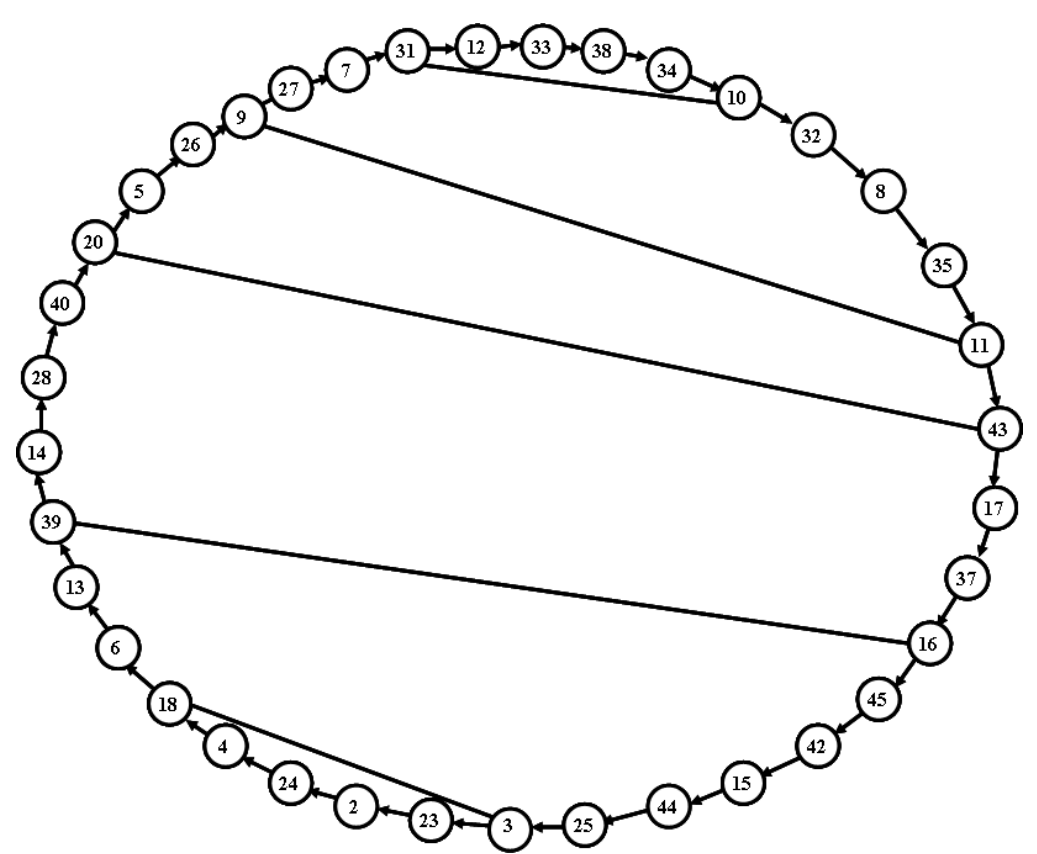

Fig. 9. Disjoint connections.

The totality of simple and isometric cycles forms the topological drawing of the planar subgraph (Fig. 10).

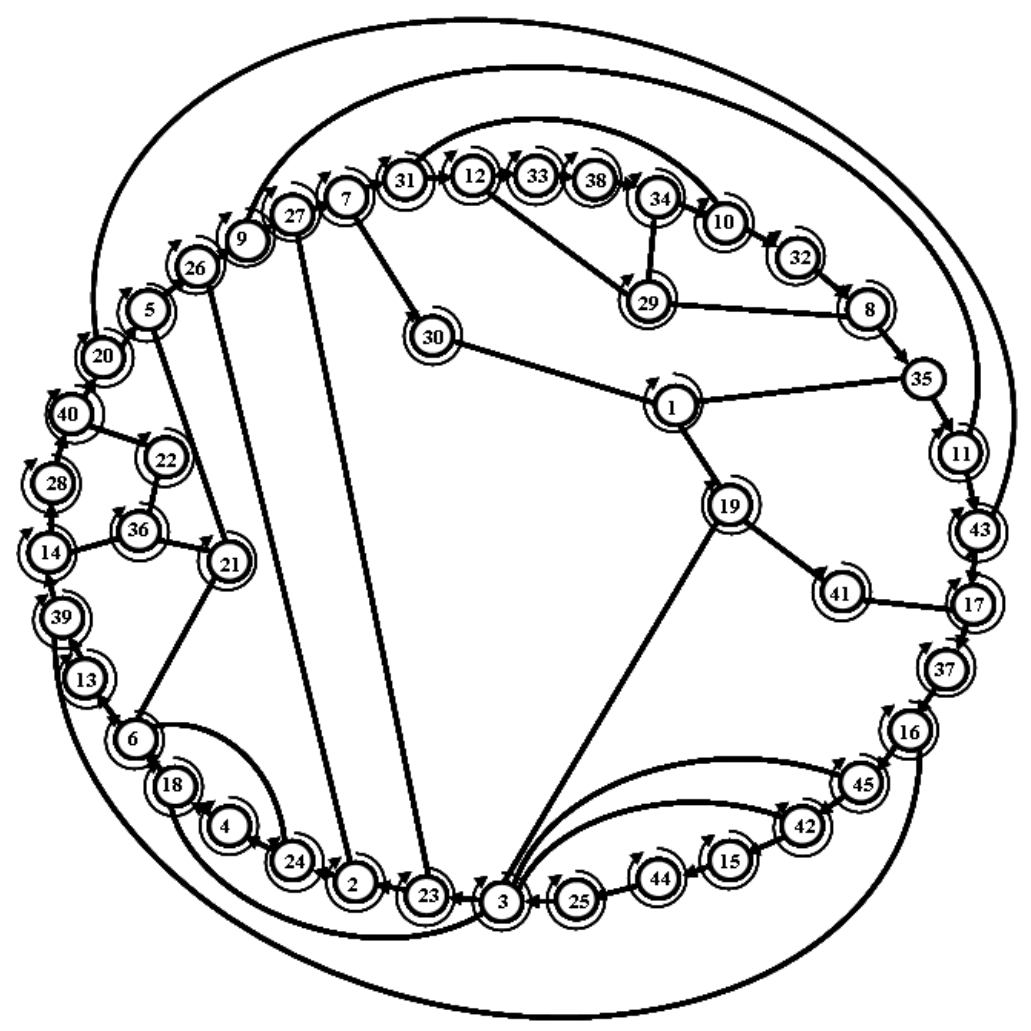

Fig. 10. Topological drawing of the planar subgraph.

\section{Conclusion}

In this paper, we consider the issues of applying the diakoptic approach for construction of a topological drawing of the planar part of a non-planar graph. It is demonstated that the solution to the problem of distinguishing the planar part for the nonseparable subgraph of a nonplanar graph consists of two stages. 
The first stage in constructing a topological drawing is based on the matroid properties of the set of graph isometric cycles. A method is proposed for isolating a topological drawing of the planar part of a non-planar graph using structural number algebra methods. The initial information for solving the problem on the first stage is the set of graph isometric cycles, which allows us to reduce the solution to discrete optimization methods.

The second stage of joining cycles is based on the methods of vector algebra of intersections. The basis of this method is the construction of a coordinate-base system, which is based on the rim of the isolated planar part of the graph obtained on the first stage of the proposed solution.

\section{References}

1. M. Gary, D. Johnson. Computing machines and hard-to-solve problems. - M.: Mir, 1982. $-416 \mathrm{p}$.

2. G. Cron. Investigation of complex systems in parts (diakoptics). Trans. with English. Moscow: Nauka, 1972. - 544 p.

3. G. Ringel. Map Color Theorem. Repr. of the orig. 1st ed. (1974), Springer, 2011. - 212 p.

4. T. Kavitha, C. Liebchen, K. Mehlhorn, D. Michail, et al. Cycle bases in graphs - characterization, algorithms, complexity, and applications // Comput. Sci. Rev. 2009. No.3. P.199243.

5. M. N. S. Swamy, K. Thulasiraman. Graphs, networks, and algorithms. - J. Wiley \& Sons, 1981.

6. S. Bellert. Analysis and synthesis of electrical circuits by the method of structural numbers / S. Bellert, G. Wozniacki. - Moscow: Mir, 1972. - 332 p.

7. S. MacLane. A combinatorial condition for planar graphs // Fund. Math., 28. - 1937. - P. 22-32.

8. S. V. Kurapov, A. V. Tolok. The topological drawing of a graph: Construction methods // Autom. Remote Control. 2013. Vol. 74, Issue 9. - P. 1494-1509.

9. Kurapov $S$. V, Davidovsky $M$. V. Construction of a general drawing of connections in planar structures // Components and technologies. - 2016. No. 3. - P. 72-77.

10. Rappoport L. I., Morogovskiy B. N., Polivtsev S. A. Vector algebra and projection of connection topology. In: Problems of Automation of Design of Integrated Circuits. - Kiev: IR of the USSR . - 1976. - P. 107-124.

11. Rappoport L. I., Morogovskiy B. N., Polivtsev S. A. Vector algebra of intersections // In: Multiprocessor computing structures. - Taganrog. - 1982. - Vyp. 2 (11). - P. 53-56. 